\title{
Inhaled granulocyte-macrophage colony stimulating factor for mild-to-moderate autoimmune pulmonary alveolar proteinosis - a six month phase II randomized study with 24 months of follow-up
}

Xinlun Tian ${ }^{1+}$, Yanli Yang ${ }^{1+}$, Lulu Chen ${ }^{2+}$, Xin Sui ${ }^{3}$, Wenshuai Xu' ${ }^{1}$, Xue Li $i^{1}$, Xiaobei Guo ${ }^{1,4}$, Lingshan Liu', Yusen Situ ${ }^{5}$, Jun Wang ${ }^{1}$, Yang Zhao ${ }^{1}$, Shuzhen Meng ${ }^{1}$, Wei Song ${ }^{3}$, Yonglong Xiao ${ }^{2^{*}}$ and Kai-Feng $\mathrm{Xu}^{1{ }^{*}}$

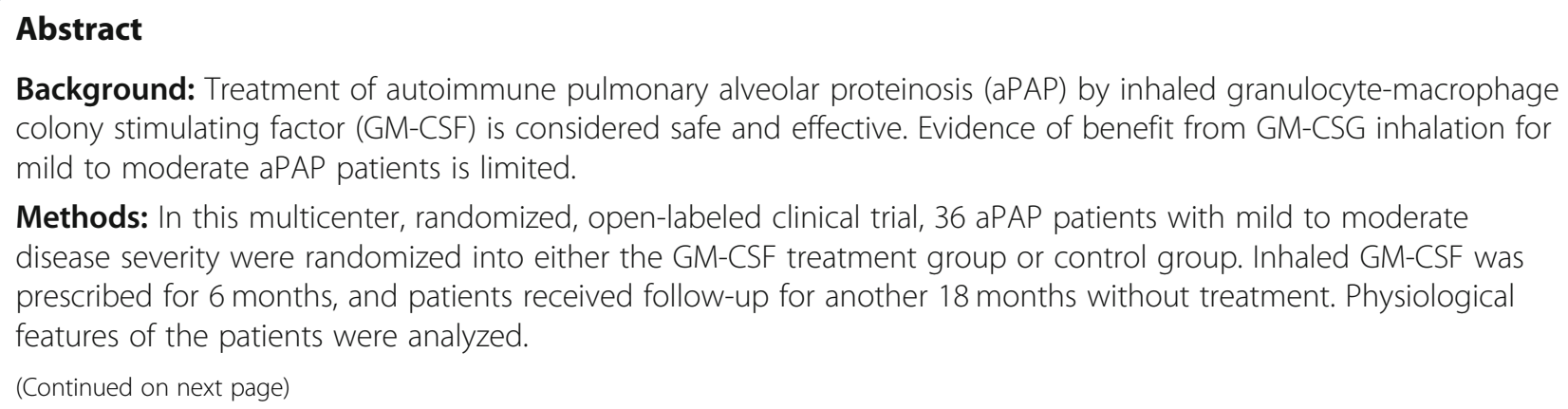
colony stimulating factor (GM-CSF) is considered safe and effective. Evidence of benefit from GM-CSG inhalation for mild to moderate aPAP patients is limited.

Methods: In this multicenter, randomized, open-labeled clinical trial, 36 aPAP patients with mild to moderate disease severity were randomized into either the GM-CSF treatment group or control group. Inhaled GM-CSF was prescribed for 6 months, and patients received follow-up for another 18 months without treatment. Physiological features of the patients were analyzed.

\footnotetext{
* Correspondence: yonglongxiao@sina.cn; xukf@pumch.cn

${ }^{+}$Xinlun Tian, Yanli Yang and Lulu Chen contributed equally to this work. ${ }^{2}$ Department of Pulmonary and Critical Care Medicine, The Affiliated Drum

Tower Hospital of Nanjing University Medical School, Jiangsu, China

'Department of Pulmonary and Critical Care Medicine, Peking Union Medical

College Hospital, Chinese Academy of Medical Sciences \& Peking Union Medical College, Beijing, China

Full list of author information is available at the end of the article
}

(C) The Author(s). 2020 Open Access This article is licensed under a Creative Commons Attribution 4.0 International License, which permits use, sharing, adaptation, distribution and reproduction in any medium or format, as long as you give appropriate credit to the original author(s) and the source, provide a link to the Creative Commons licence, and indicate if changes were made. The images or other third party material in this article are included in the article's Creative Commons licence, unless indicated otherwise in a credit line to the material. If material is not included in the article's Creative Commons licence and your intended use is not permitted by statutory regulation or exceeds the permitted use, you will need to obtain permission directly from the copyright holder. To view a copy of this licence, visit http://creativecommons.org/licenses/by/4.0/ The Creative Commons Public Domain Dedication waiver (http://creativecommons.org/publicdomain/zero/1.0/) applies to the data made available in this article, unless otherwise stated in a credit line to the data. 
(Continued from previous page)

Results: There were 36 patients (19 in the treatment group, 17 in the control group) included. There were no significant differences in the primary endpoints as measured by the change of alveolar arterial oxygen gradient (A$\mathrm{aDO}_{2}$ ) from the baseline values to the values obtained during treatment or during the following 18-month nontreatment observation period [control group vs. treatment group: $0.51 \pm 12.09 \mathrm{mmHg}$ vs. $-0.35 \pm 13.76 \mathrm{mmHg}, p=$ 0.848 (3 month); $1.85 \pm 11.21 \mathrm{mmHg}$ vs. $7.31 \pm 8.81 \mathrm{mmHg}, p=0.146$ (6 months); $6.05 \pm 11.14 \mathrm{mmHg}$ vs. $6.61 \pm 10.64$ $\mathrm{mmHg}, p=0.899$ (24 months)]). Percentage of diffusion capacity predicted (DLCO\%) and percentage of total lung capacity predicted (TLC\%), however, were significantly improved in the treatment group by the end of the study $(P=0.010$ and 0.027$)$. St. George Respiratory questionnaire (SGRQ) scores were better after 6 months treatment with GM-CSF compared to the control group, and the benefits of treatment were maintained throughout the observation period. No severe side effects were observed during the study.

Conclusion: Six months of inhaled GM-CSF treatment had no effect on the alveolar-arterial oxygen gradient in patients with mild to moderate pulmonary alveolar proteinosis. There were changes in some clinical or laboratory measures, but no clinically important changes were noted at the end of study. (Clinical Trial Registry: NCT02243228, Registered on September 17, 2014, https://www.clinicaltrials.gov/ct2/show/NCT02243228?term=NCT0224322 $8 \&$ draw $=2 \&$ rank $=1$ )

Keywords: Autoimmune pulmonary alveolar proteinosis, Granulocyte-macrophage colony stimulating factor, Inhalation

\section{Background}

Autoimmune pulmonary alveolar proteinosis (aPAP, previously known as idiopathic PAP) is a rare interstitial lung disease elicited by the formation of autoantibodies which neutralize the activity of granulocyte-macrophage colony stimulating factor (GM-CSF), consequently decreasing macrophage clearance of surfactant [1]. Currently, the standard treatment strategy for PAP is whole lung lavage (WLL). About 70\% patients need another WLL within 3 years due to recurrence $[2,3]$. Patients who undergo WLL require general anesthesia and double-lumen endotracheal intubation, which means only hospitals with experienced physicians can perform the procedure. Considering the recurrence rate and the cumbersome procedure of WLL, whether or not patients with mild or moderate disease should obtain that treatment is a matter of controversy.

Inhaled GM-CSF therapy has become an attractive alternative option for aPAP patients not only due to its effectiveness and safety $[4,5]$, but also because it is a convenient treatment method for patients who are reluctant to receive WLL. Previous studies included small sample sizes, and as a result, disease severity has not been stratified. Nevertheless, whether patients with mild or moderate disease will benefit from GM-CSF treatment over the long term is still unclear. We prospectively evaluated if inhaled GM-CSF would delay disease progression in patients with mild-to moderate aPAP over a two-year period.

\section{Methods}

\section{Participants}

Patients with mild or moderate aPAP, aged between 18 and 80 years old, were enrolled at two hospitals, including Peking Union Medical College Hospital (PUMCH) and The Affiliated Drum Tower Hospital of Nanjing University Medical School in China.

The inclusion criteria included: (1) patients with a clinical diagnosis of PAP by high-resolution computed tomography (HRCT), further pathologically confirmed by testing for amorphous periodic Acid-Schiff (PAS)positive granules; (2) a positive serum GM-CSF antibody test which indicated an elevated serum GM-CSF antibody level; and (3) patients eligible for the trial should have progressive or unremitting PAP, defined as worsening or unchanging $\mathrm{PaO}_{2}$ or $\mathrm{A}-\mathrm{aDO}_{2}$ over a 3-month period of observation. PAS-positive granules were found either in milky broncho-alveolar lavage fluid (BALF) or in alveolar structures of lung biopsy tissues which were obtained as follows: cytological findings of bronchial lavage fluid only (BAL) $(n=13)$, transbronchial lung biopsy only (TBLB) $(n=7)$, both TBLB and BAL $(n=12)$, percutaneous lung puncture biopsy $(n=3)$, and surgical lung biopsy only $(n=1)$. The GM-CSF antibody test was performed according to the method established by Uchida et al. [6, 7]. Our hospital set the cutoff point at $2.39 \mathrm{~g} / \mathrm{mL}$, with measurements in excess of this value resulting a positive report [8].

Disease severity was assessed with a disease severity score (DSS), with patients with a DSS of 1 to 3 inclusive being included in our study. DSS scores were defined by Inoue et al. as follows [3]: Grade 1: No symptoms and an arterial oxygen partial pressure $\left(\mathrm{PaO}_{2}\right) \geq 70 \mathrm{mmHg}$; Grade 2: $\mathrm{PaO}_{2} \geq 70 \mathrm{mmHg}$ with symptoms; Grade 3: $\mathrm{PaO}_{2}$ between 60 and $70 \mathrm{mmHg}$; Grade 4: $\mathrm{PaO}_{2}$ between 50 and $60 \mathrm{mmHg}$; and Grade 5: $\mathrm{PaO}_{2}$ below $50 \mathrm{mmHg}$.

Individuals were excluded if they met the following criteria: (1) patients had already received previous GM- 
CSF therapy or other forms of cytokine therapy, or had undergone lung lavage therapy within the 3 months prior to enrollment; (2) Individuals with PAP resulting from other conditions (e.g. occupational exposure to silica, underlying human immunodeficiency virus infection, respiratory infections, myeloproliferative disorder or leukemia); (3) Individuals with histories of severe allergic or anaphylactic reactions to humanized or murine monoclonal antibodies; (4) Individuals with chronic lung diseases or any other serious medical conditions, or (5) Women who were pregnant, lactating or planned to become pregnant during the study period.

\section{Study design}

This was a multicenter, randomized, open-label clinical trial (clinical trial number: NCT02243228, Inhalation of granulocyte-macrophage colony stimulating factor for autoimmune pulmonary alveolar proteinosis) comprising three sequential periods: high-dose therapy for 3 months, low-dose therapy for 3 months and observation for 18 months. Study visits during treatment were designed at $0,1,3$ and 6 months. Thereafter, patients were followed up by visits at $9,12,15,18,21$ and 24 months (Fig. 1). Patients' safety questionnaires were reviewed by telephone at 1, 15 and 21 months. Before the therapeutic trial, all participants entered an initial 3-month observation period, during which disease severity and progression were evaluated. Participants that had their $\mathrm{PaO}_{2}$ increase by $10 \mathrm{mmHg}$ or more, or alveolar-arterial oxygen gradient $\left(\mathrm{A}-\mathrm{aDO}_{2}\right)$ decrease by $10 \mathrm{mmHg}$ or more were regarded as having undergone spontaneous improvement and were excluded from enrollment. It should be noted that if a participant was acquainted to the principal investigator as a patient with a welldocumented history showing an unremitting aPAP state, he/she could be enrolled into the study without this observation period. After 3-months of observation, all unremitting PAP patients underwent a stratified randomization based on their DSS at the time of enrollment to ensure equal representation of patients with various disease severities in both the treatment group and the placebo group using a random number table. The randomization was blinded to both the patients and the investigators.

Recombinant human GM-CSF (rhGM-CSF) was administered to patients in treatment group by inhalation as previously described [9]. $150 \mu \mathrm{g}$ of rhGM-CSF was dissolved in $2 \mathrm{ml}$ of sterile saline, and was inhaled as an aqueous aerosol using an LC-PLUS nebulizer with a manual interrupter valve connected to a PARI Turbo BOY compressor (PARI GmbH, Starnberg, Germany) [10]. Treatment was designed according to a previous study [11], including 3 months of high-dose GM-CSF administration $(150 \mu \mathrm{g}$ twice daily every other week) and another 3 months of low-dose administration $(150 \mu \mathrm{g}$ once daily every other week), serving as induction and maintenance therapy, respectively.

In the control group, patients were not prescribed any kind of treatment related to PAP (including GM-CSF, WLL or anti-CD20, etc.) but had the same follow up plan as the treatment group.

In previous published studies, patients inhaling GMCSF had a mean change in $\mathrm{A}-\mathrm{aDO}_{2}$ of $11 \mathrm{mmHg}$ [11]. Thus, the target sample size was 25 , chosen to give a detection power of $90 \%$, allowing for a $5 \%$ incidence of type-I error. After taking other outcome measurements and participant dropout into consideration, the study size was increased to $35-45$ patients.

The study was approved by the institutional review board of PUMCH (Approval No. S-717) and reviewed by the institutional review boards at the Affiliated Drum Tower Hospital of Nanjing University Medical School.

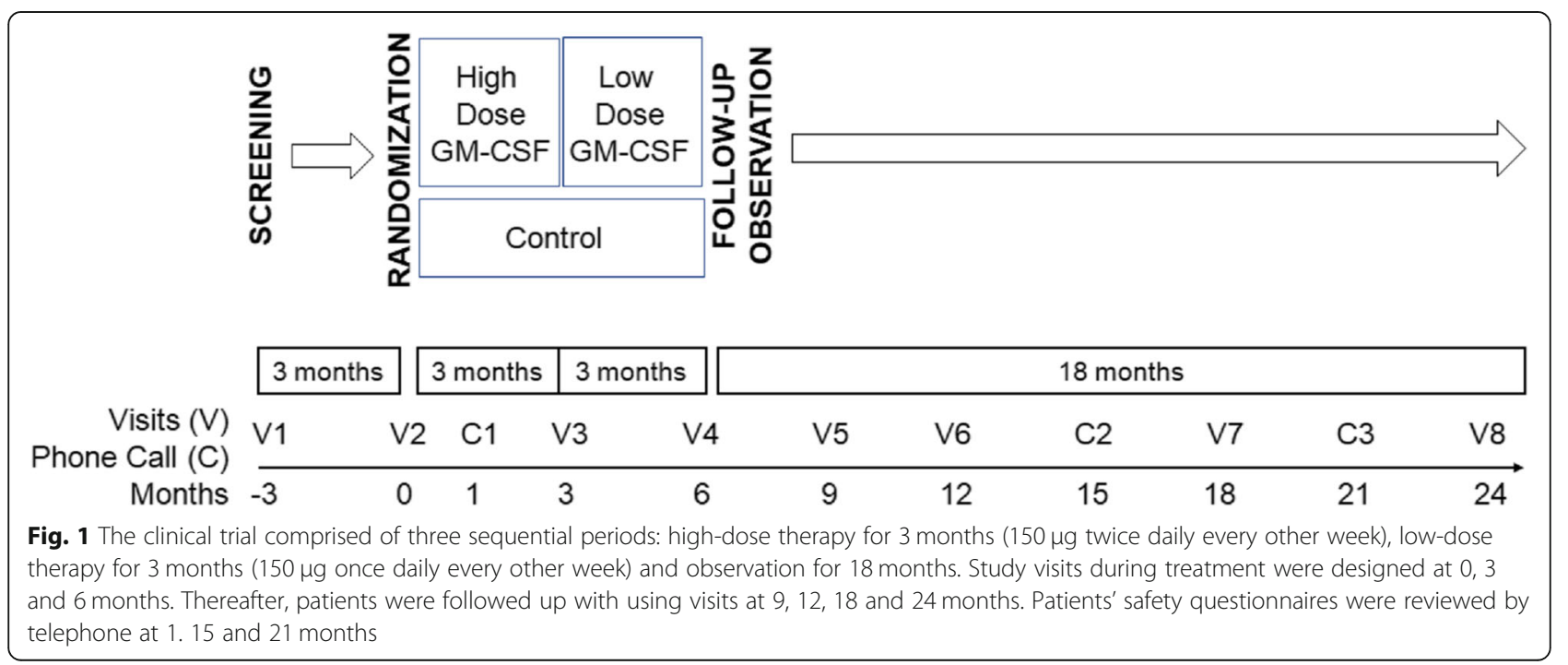


All participants provided informed written consent prior to enrollment.

\section{Assessments}

Clinical information including history, symptoms, serological (including lactate dehydrogenase, carcinoembryonic antigen levels) and radiological features, pulmonary function testing results and physical examination results were obtained at each visit during the study. Arterial blood gas analysis (ABG) tests were performed with patients that had been breathing room air for at least 15 min. A low dose quantitative computed tomography of the chest (in PUMCH) or high resolution CT (HRCT) of the chest (in The Affiliated Drum Tower Hospital of Nanjing University Medical School) was obtained before and after GM-CSF therapy and evaluated in a blinded fashion by a board-certified radiologist. The original CT measurements were collected, and the total lung volume and mean lung density were automatically calculated and post-processed with Pulmo 3D (syngo. Via, version VA 30, Siemens Healthcare, Germany) for the automatic segmentation of the pulmonary parenchyma by excluding the intrapulmonary vessels following the process published by one of our co-authors, Dr. Sui [12].

Intergroup differences in the change of $\mathrm{A}-\mathrm{aDO}_{2}$ from baseline to the end of treatment were defined as primary endpoints.

Other data, representing the efficacy of GM-CSF inhalation, were also evaluated as secondary endpoints, including pulmonary function test differences between the treatment group and the control group (forced vital capacity [FVC], total lung capacity [TLC], diffusing capacity for carbon monoxide [DLCO] or diffusing capacity for carbon monoxide corrected for alveolar volume [DLCO/ VA]), 6 min walking distance differences between the groups, and relapse time in the two groups. The definition of relapse was as follows: 1) a new requirement for whole lung lavage (WLL) or any other kind of treatment (including traditional medicine, subcutaneous injection or GM-CSF inhalation) due to disease progression; or 2) PAP death; or 3) reduction in $\mathrm{PaO}_{2}$ of more than 10 $\mathrm{mmHg}$, or increase in $\mathrm{A}-\mathrm{aDO}_{2}$ of more than $10 \mathrm{mmHg}$; or 4) a worsened chest HRCT independently confirmed by two physicians. Monitoring for adverse events was conducted during the study, looking for airway hypersensitivity, fever, mylagia, arrhythmia and potential effects on the circulatory system.

All blood tests were performed in laboratories affiliated with the two hospitals, both of which have China's quality management certification. Serum levels of GMCSF antibody were tested at PUMCH.

All of the data was collected and stored in the database system founded by Beijing Yikang Healthcare Technology Co.

\section{Statistical analysis}

All statistical analyses were performed using SPSS 20.0 software. Numeric results were presented as either the mean \pm SD or the median and inter-quartile range. Metric variables were shown as the mean and categorical variables were given in terms of frequencies and percentages. The $X^{2}$ test was used to analyze proportions of variables. For group comparisons, the unpaired $t$ tests and Wilcoxon rank-sum test were used to evaluate the differences in normally distributed variables. Kaplan-Meier Curve analysis was used to analyze time for relapse in the two groups. All $P$ values reported were two-sided.

\section{Results}

\section{Baseline demographic information}

Forty-two aPAP patients were screened and 36 patients were randomized (19 in the treatment group and 17 in the control group). After 24 months of follow up, 26 patients $(72.2 \%, 15$ from the treatment group and 11 from the control group) completed the study. The period of recruitment and follow up was from July 20, 2014 to July 6, 2018 after the last enrolled patient completed his 24 months follow up. In the treatment group, one patient deteriorated at 3 months and required rescue therapy (WLL). Another patient lost follow up at 1 month and two more patients withdrew at 6 months. In the control group, 4 patients deteriorated at 3 months and required rescue therapy (one received GM-CSF inhalation, two received WLL and one was prescribed traditional medicine). 2 patients withdrew at 21 months. (Fig. 2).

In 36 patients, the most common presenting symptom was dyspnea $(20 / 36,55.6 \%)$, followed by cough $(13 / 36$, $36.1 \%)$, phlegm $(6 / 36,16.7 \%)$ and chest pain $(3 / 36$, $8.3 \%)$. 4 out of our 36 patients were diagnosed by regular health check-up without any symptoms. The median duration of symptoms is 6 months (inter-quartile range is from 0 to 60 months) in our patients. All of our patients had extent bilateral pulmonary infiltrates confirmed by HRCT.

Demographic information of the 36 patients entered the study is shown in Table 1. There were no significant differences in demographic information between the treatment group and the control group including age and sex. No significant differences were found in patients' disease severity markers at baseline, including symptoms, ABG, pulmonary function tests, $6 \mathrm{~min}$ walking distance (6MWD) and anti-GM-CSF antibody levels between the two groups.

\section{Primary endpoint: $\mathrm{A}-\mathrm{aDO}_{2}$}

There were no significant differences between the treatment group and control group based on primary endpoints measured by the change of $\mathrm{A}-\mathrm{aDO}_{2}$ from baseline to 3 and 6 months treatment and during the following 


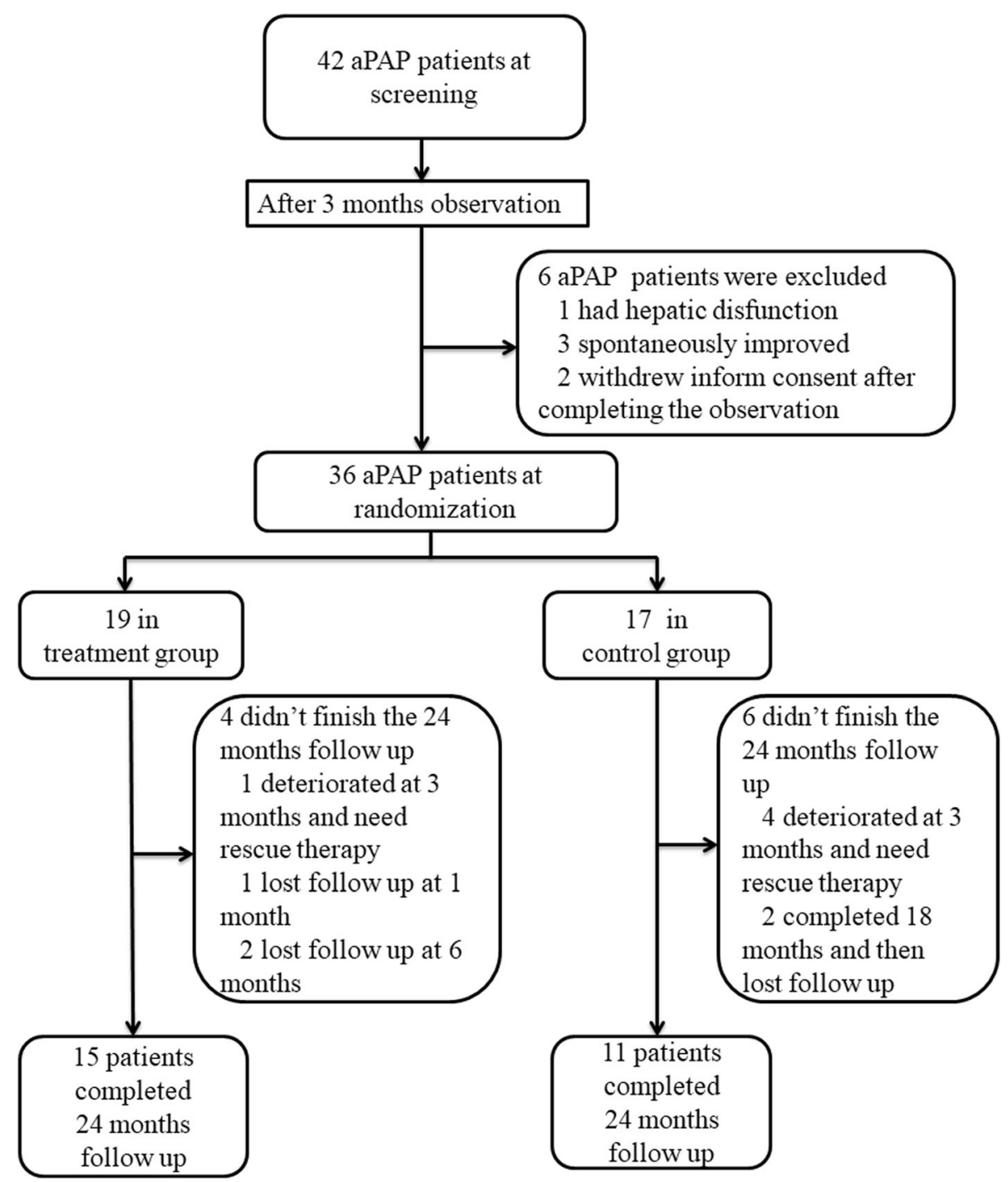

Fig. 2 Flow diagram of the study cohort. aPAP: autoimmune pulmonary alveolar proteinosis; GM-CSF: granulocyte-macrophage colony stimulating factor

18 months [control group vs. treatment group: $0.51 \pm$ $12.09 \mathrm{mmHg}$ vs. $-0.35 \pm 13.76 \mathrm{mmHg}, p=0.848$ (at 3 months); $1.85 \pm 11.21 \mathrm{mmHg}$ vs. $7.31 \pm 8.81 \mathrm{mmHg}, p=$ 0.146 (at 6 months); $6.05 \pm 11.14 \mathrm{mmHg}$ vs. $6.61 \pm 10.64$ $\mathrm{mmHg}, p=0.899$ (at 24 months)] (Fig. 3a). The change of $\mathrm{PaO}_{2}$ level from baseline to 3 and 6 months treatment, and during the following 18 months also showed no significant difference between the two groups (Fig. 3b). The actual level of $\mathrm{A}-\mathrm{aDO}_{2}$ and $\mathrm{PaO}_{2}$ showed no differences during both the treatment period and follow up period as well (Fig. 3c and d) (Tables 2 and 3).

\section{The diffusion capacity and total lung capacity were} improved by the end of study

Significant differences in DLCO\% and TLC\% between the treatment group and the control group emerged by the end of the study (Fig. 4a and b). [DLCO\% (control group vs. treatment group): $67.12 \pm 14.72$ vs. $69.19 \pm 19.83, \quad p=0.732 \quad$ (at 3 months); $70.83 \pm 14.62$ vs. $74.91 \pm 14.80, p=0.465$ (at 6 months); $64.67 \pm 16.22$ vs. $80.87 \pm 19.40, p=0.027$ (at 24 months)]. [TLC\% (control group vs. treatment group): $74.09 \pm 11.37$ vs. $73.12 \pm 15.29, p=0.836$ months); $74.28 \pm 11.18$ vs. $78.48 \pm 8.88, p=0.269$ months); $70.97 \pm 10.79$ vs. $79.77 \pm 7.76, p=0.010$ months)]. However, there were no significant differences between the treatment group and the control group in terms of other pulmonary function tests, including $\mathrm{FVC}, \mathrm{FEV}_{1}$ (data not shown) and DLCO/ $\mathrm{VA}$, both during the 6-month treatment period and the 18-month follow-up period (Fig. 4c and d) (Table 2 and supplemental table 1). 
Table 1 Demographic features of autoimmune pulmonary alveolar proteinosis (aPAP) patients at baseline

\begin{tabular}{|c|c|c|c|c|}
\hline \multicolumn{2}{|l|}{ Parameter } & $\begin{array}{l}\text { Control group } \\
(n=17)\end{array}$ & Treatment group $(n=19)$ & $P$ value \\
\hline \multicolumn{2}{|l|}{ Age (year) } & $42.88 \pm 12.75$ & $43.53 \pm 12.89$ & 0.881 \\
\hline \multicolumn{2}{|l|}{ Sex (female/male) } & $4 / 13$ & $6 / 13$ & 0.717 \\
\hline \multicolumn{2}{|c|}{ Duration of the disease (months) ${ }^{a}$} & $6(6-60)$ & $6(0.5-60)$ & 0.852 \\
\hline \multirow[t]{3}{*}{ Smoking status } & Never & 7 & 7 & \multirow[t]{3}{*}{0.965} \\
\hline & Ex-smoker & 5 & 6 & \\
\hline & Current smoker & 5 & 6 & \\
\hline \multirow[t]{3}{*}{ Disease Severity Score } & 1 & 0 & 0 & \multirow[t]{3}{*}{0.409} \\
\hline & 2 & 13 & 11 & \\
\hline & 3 & 4 & 8 & \\
\hline \multicolumn{2}{|l|}{$\mathrm{Hb}(\mathrm{g} / \mathrm{dL})$} & $16.11 \pm 1.61$ & $16.00 \pm 1.64$ & 0.839 \\
\hline \multicolumn{2}{|l|}{ HCT (\%) } & $46.07 \pm 3.7$ & $45.74 \pm 4.47$ & 0.810 \\
\hline \multicolumn{2}{|l|}{$\mathrm{LDH}(\mathrm{U} / \mathrm{L})$} & $244.06 \pm 53.02$ & $233.82 \pm 43.43$ & 0.547 \\
\hline \multicolumn{2}{|l|}{ CEA (U/L) } & $5.34 \pm 4.96$ & $4.74 \pm 3.41$ & 0.678 \\
\hline \multicolumn{2}{|l|}{$\mathrm{FEV}_{1}$ pred (\%) } & $78.09 \pm 14.12$ & $79.16 \pm 15.68$ & 0.832 \\
\hline \multicolumn{2}{|l|}{ FVC pred (\%) } & $79.14 \pm 13.42$ & $79.71 \pm 13.70$ & 0.900 \\
\hline \multicolumn{2}{|l|}{ TLC pred (\%) } & $74.59 \pm 9.65$ & $74.82 \pm 10.78$ & 0.946 \\
\hline \multicolumn{2}{|l|}{ DLCO pred (\%) } & $69.50 \pm 13.94$ & $68.41 \pm 16.90$ & 0.835 \\
\hline \multicolumn{2}{|l|}{ DLCONA pred (\%) } & $98.58 \pm 18.45$ & $98.67 \pm 24.32$ & 0.990 \\
\hline \multicolumn{2}{|l|}{$\mathrm{PaO}_{2}(\mathrm{mmHg})$} & $77.51 \pm 8.53$ & $76.88 \pm 11.23$ & 0.854 \\
\hline \multicolumn{2}{|l|}{$\mathrm{A}-\mathrm{aDO} \mathrm{O}_{2}(\mathrm{mmHg})$} & $28.32 \pm 9.09$ & $28.74 \pm 11.04$ & 0.902 \\
\hline \multicolumn{2}{|l|}{ SGRQ symptom } & $24.06 \pm 13.55$ & $29.17 \pm 29.75$ & 0.506 \\
\hline \multicolumn{2}{|l|}{ SGRQ activity } & $30.70 \pm 18.46$ & $30.33 \pm 16.55$ & 0.949 \\
\hline \multicolumn{2}{|l|}{ SGRQ effect } & $24.20 \pm 16.10$ & $21.83 \pm 21.29$ & 0.712 \\
\hline \multicolumn{2}{|l|}{ SGRQ total } & $26.47 \pm 14.74$ & $27.38 \pm 19.75$ & 0.878 \\
\hline \multicolumn{2}{|l|}{ 6MWD } & $495.25 \pm 79.39$ & $477.95 \pm 65.68$ & 0.485 \\
\hline \multicolumn{2}{|l|}{$\mathrm{SpO}_{2}$ at the end of $6 \mathrm{MWD}$} & $94.87 \pm 2.70$ & $94.58 \pm 5.20$ & 0.847 \\
\hline \multicolumn{2}{|l|}{ Mean lung density } & $-718.62 \pm 82.70$ & $-687.25 \pm 68.48$ & 0.315 \\
\hline \multicolumn{2}{|c|}{ Total lung volume radiological measurement (ml) } & $4556.08 \pm 841.15$ & $4461.08 \pm 1399.60$ & 0.841 \\
\hline \multicolumn{2}{|l|}{ GM-CSF antibody $(\boldsymbol{\mu} \mathrm{g} / \mathrm{ml})$} & $75.86 \pm 93.94$ & $73.30 \pm 58.65$ & 0.922 \\
\hline \multirow[t]{3}{*}{ Treatment before the trial } & Never & 13 & 14 & \multirow[t]{3}{*}{0.489} \\
\hline & WLL & 3 & 5 & \\
\hline & Others $^{b}$ & 1 & 0 & \\
\hline
\end{tabular}

Abbreviations: aPAP autoimmune pulmonary alveolar proteinosis, $A-a O_{2}$ alveolar arterial oxygen gradient, $C E A$ carcinoembryonic antigen, DLCO: DLCO: diffusing capacity for carbon monoxide, DLCONA diffusing capacity for carbon monoxide corrected for alveolar volume, FEV1 forced expiratory volume in the first second, FVC forced vital capacity, GM-CSF granulocyte macrophage colony stimulating factor, $\mathrm{Hb}$ hemoglobin, $\mathrm{HCT}$ hematocrit, $\mathrm{LDH}$ lactate dehydrogenase, $\mathrm{PaO}, \mathrm{Partial}$ pressure of oxygen, SGRQ St George Respiratory Questionnaire, $\mathrm{SpO}_{2}$ oxygen saturation in pulse oximetry, $T L C$ total lung capacity, $6 M W D 6$ min walking distance (test)

a: median (inter-quartile range)

b:Traditional medicine treatment

The SGRQ scores increased after 3 months and 6 months of inhaled GM-CSF treatment and 18 months follow-up Meanwhile, we can see obvious differences in patients' quality of life between the treatment group and control group, as measured by SGRQ. Total SGRQ scores in patients in the treatment group was improved after 6 months of GM-CSF treatment compared to the no treatment group, and the benefits were nearly continuously maintained throughout the 18- month observation period. Similar trends can be observed in symptom score, activity score and effect score, although significant differences between the two groups were not observed at all times (Fig. 5).

\section{Quantitative CT did not find difference after treatment}

There were no significant differences in total lung volume and mean lung density between the treatment 


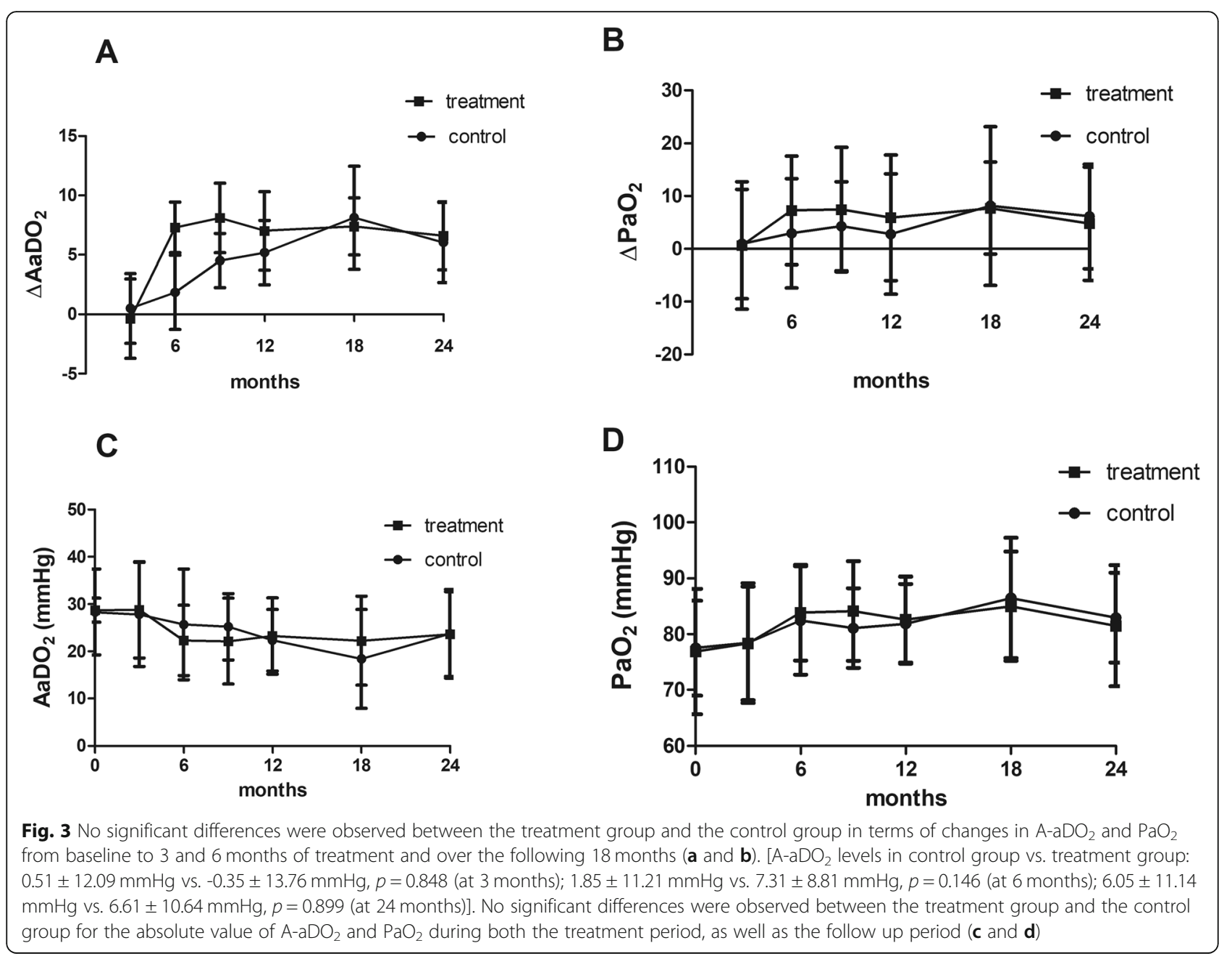

group and control group (Table 2 and supplemental Table 1).

Time to rescue therapy during the 24-month study was not improved

There was no significant difference in time to rescue therapy between the treatment group and control group. Kaplan-Meier Curve analysis for the two groups was shown in Fig. $6(P=0.304)$.

\section{Safety and tolerability of inhaled GM-CSF}

None of our patients died during the trial. None of the patients in the treatment group complained of fever, wheezing or coughing over the duration of their inhaled GM-CSF treatment.

An increase in transaminase levels during GM-CSF inhalation treatment was observed $(P=0.037)$. Fortunately, none of the patients required medical intervention. The highest observed level of transaminase in the GM-CSF treatment group was $123 \mathrm{U} / \mathrm{L}$ for alanine aminotransferase (ALT) and $63 \mathrm{U} / \mathrm{L}$ for aspartate aminotransferase (AST), while the highest observed level in the control group was $95 \mathrm{U} / \mathrm{L}$ for ALT and $77 \mathrm{U} / \mathrm{L}$ for AST respectively. All parameters remained stable or gradually declined after patients ceased alcohol consumption and stopped taking medications with possible interfering effects. Peripheral blood neutrophils levels were not obviously increased within the GM-CSF inhalation group when compared to the control group $(P=0.429)$ (Table 4).

No other significant safety and tolerability differences were observed between the two groups during the study.

Other details of side effects that occurred during the study can be found in the supplementary data.

\section{Discussion}

In this study, we prospectively evaluated the effects of inhaled GM-CSF on mild-to-moderate autoimmune pulmonary alveolar proteinosis (aPAP) patients. In contrast to previous reports, no obvious effects were found in our 
Table 2 The clinical parameter of the effects of inhaled GM-CSF during the 6 months treatment periods

\begin{tabular}{|c|c|c|c|c|c|c|}
\hline & \multicolumn{3}{|l|}{3 months } & \multicolumn{3}{|l|}{6 months } \\
\hline & Control group $(n=17)$ & Treatment group $(n=17)$ & $P$ value & Control group $(n=13)$ & Treatment group $(n=17)$ & $P$ value \\
\hline$\Delta \mathrm{A}-\mathrm{aDO} 2(\mathrm{mmHg})$ & $0.51 \pm 12.09$ & $-0.35 \pm 13.76$ & 0.848 & $1.85 \pm 11.21$ & $7.31 \pm 8.81$ & 0.146 \\
\hline $\mathrm{A}-\mathrm{aDO} \mathrm{Z}_{2}(\mathrm{mmHg})$ & $27.81 \pm 11.04$ & $28.79 \pm 10.19$ & 0.794 & $25.69 \pm 11.70$ & $22.31 \pm 7.45$ & 0.342 \\
\hline$\Delta \mathrm{PaO}_{2}(\mathrm{mmHg})$ & $0.92 \pm 10.34$ & $0.62 \pm 12.07$ & 0.94 & $2.95 \pm 10.34$ & $7.26 \pm 10.29$ & 0.267 \\
\hline $\mathrm{PaO}_{2}(\mathrm{mmHg})$ & $78.42 \pm 10.74$ & $78.37 \pm 10.17$ & 0.988 & $82.42 \pm 9.71$ & $83.84 \pm 8.57$ & 0.589 \\
\hline FVC pred (\%) & $77.24 \pm 14.91$ & $78.48 \pm 13.72$ & 0.801 & $80.41 \pm 15.60$ & $77.34 \pm 23.32$ & 0.688 \\
\hline TLC pred (\%) & $74.09 \pm 11.37$ & $73.12 \pm 15.29$ & 0.836 & $74.28 \pm 11.18$ & $78.48 \pm 8.88$ & 0.269 \\
\hline DLCO pred (\%) & $67.12 \pm 14.72$ & $69.19 \pm 19.83$ & 0.732 & $70.83 \pm 14.62$ & $74.91 \pm 14.80$ & 0.465 \\
\hline DLCONA pred (\%) & $95.67 \pm 17.32$ & $98.71 \pm 21.03$ & 0.641 & $98.92 \pm 12.47$ & $95.93 \pm 15.44$ & 0.577 \\
\hline SGRQ symptom & $24.84 \pm 17.33$ & $24.22 \pm 23.32$ & 0.521 & $29.50 \pm 18.61$ & $18.47 \pm 19.29$ & 0.097 \\
\hline SGRQ activity & $33.45 \pm 19.35$ & $24.31 \pm 18.92$ & 0.173 & $28.98 \pm 18.78$ & $19.41 \pm 17.10$ & 0.149 \\
\hline SGRQ effect & $16.38 \pm 15.94$ & $17.11 \pm 17.86$ & 0.336 & $21.58 \pm 17.60$ & $9.29 \pm 10.73$ & 0.023 \\
\hline SGRQ total & $14.76 \pm 14.52$ & $20.45 \pm 17.55$ & 0.285 & $25.11 \pm 16.36$ & $13.88 \pm 10.91$ & 0.030 \\
\hline 6MWD & $494.06 \pm 75.43$ & $496.41 \pm 75.43$ & 0.926 & $475.09 \pm 85.31$ & $501.13 \pm 88.31$ & 0.452 \\
\hline Mean lung density & NA & NA & & $-739.64 \pm 82.70$ & $-733.17 \pm 61.41$ & 0.804 \\
\hline Total lung volume (ml) & NA & NA & & $4485.71 \pm 971.37$ & $4365.67 \pm 1322.58$ & 0.808 \\
\hline $\mathrm{Hb}(\mathrm{g} / \mathrm{dL})$ & $15.42 \pm 1.53$ & $15.34 \pm 1.42$ & 0.863 & $15.65 \pm 1.79$ & $15.70 \pm 1.60$ & 0.932 \\
\hline HCT (\%) & $44.35 \pm 3.54$ & $44.52 \pm 3.48$ & 0.881 & $45.10 \pm 4.04$ & $45.50 \pm 4.46$ & 0.792 \\
\hline $\mathrm{LDH}(\mathrm{U} / \mathrm{L})$ & $226.88 \pm 46.22$ & $223.86 \pm 59.32$ & 0.867 & $230.36 \pm 28.96$ & $203.38 \pm 60.36$ & 0.130 \\
\hline CEA (U/L) & $3.72 \pm 3.31$ & $4.87 \pm 3.68$ & 0.619 & $4.40 \pm 2.25$ & $3.14 \pm 1.74$ & 0.076 \\
\hline
\end{tabular}

Abbreviations: See Table 1

study. During the 6 months of treatment and 18 month of subsequent observation, the primary endpoint, A$\mathrm{aDO}_{2}$ remained unchanged. Health-related quality of life, measured using SGRQ improved after 3 months of treatment, with these improvements and maintained to 24 months. Marginal improvement was also noted in terms of TLC and DLCO by the end of the study. This research provides valuable clinical data and experience for inhaled GM-CSF treatment in aPAP patients who do not meet the criteria for WLL.

The current therapy for PAP patients involves the physical removal of surfactant using a procedure in which the lungs are repeatedly filled with saline and emptied - WLL - which is invasive, inefficient, and is not widely available. Some authors reported that fever, hypoxemia, fluid leakage and other complications occurred in patients treated with WLL [13]. Additionally, the median time to next WLL is around 15 months [14], and about $30-57.6 \%$ of patients require further therapy after their first WLL $[15,16]$. Though there is currently no consensus, most physicians believe that patients with $\mathrm{PaO}_{2}$ less than $70 \mathrm{mmHg}$ when breathing room air or an alveolar-arterial [A-a] oxygen gradient of more than 40 $\mathrm{mmHg}$, or patients with disease progression should receive WLL as treatment [13]. In a cohort study from our center, 33\% of patients are stable or experience spontaneous remission [16], while the spontaneous remission rate varies from 8 to $18 \%$ in different reports $[11,14,16,17]$. Considering the occurrence of spontaneous remission in some patients, it becomes a critical question whether GMCSF inhalation could become a primary treatment for mild to moderate aPAP patients.

After GM-CSF was confirmed to play an important role in the disease mechanism of aPAP, the efficacy of exogenous GM-CSF replacement was assessed in a previous paper. The response rate to this treatment varied, with the efficacy rate being between 62 and 100\% when using inhaled GM-CSF $[5,11,18]$ while the efficacy rate was $43-75 \%$ when using subcutaneously administered GM-CSF $[19,20]$. Due to its better responsiveness and tolerance, the use of inhaled GM-CSF is generally recommended [4].

In previous studies, inhaled GM-CSF treatment was prescribed to patients with moderate to severe disease $[9,21-24]$, with the mean $\mathrm{PaO}_{2}$ level in a large prospective study of inhaled GM-CSF treatment on aPAP patients being $61.7 \pm 1.4 \mathrm{mmHg}$ [11]. During the preparation of our manuscript, a randomized placebocontrolled study of inhaled GM-CSF was published, with $\mathrm{A}-\mathrm{aDO}_{2}$ and $\mathrm{CT}$ density quantitative measurement being 


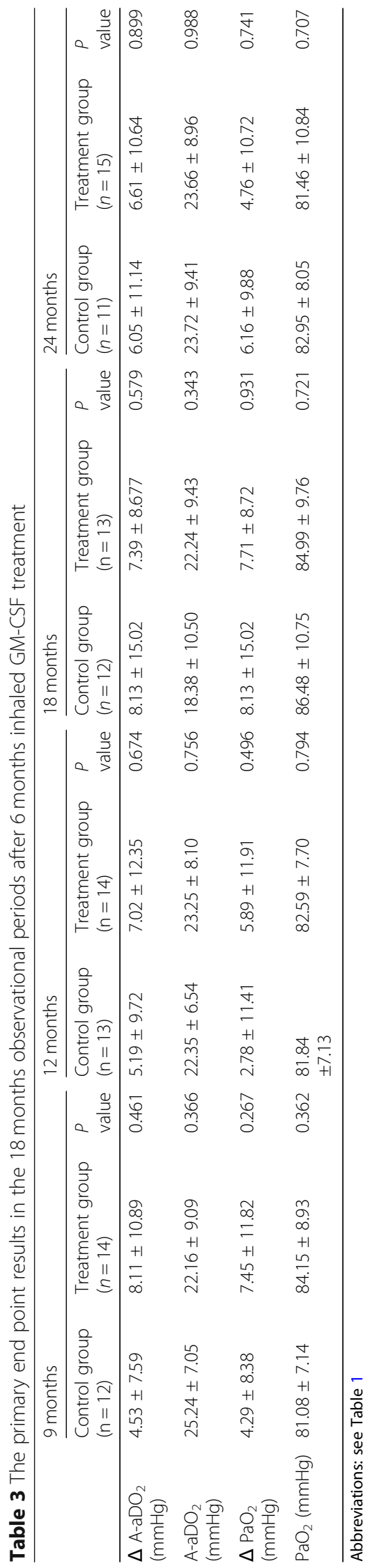




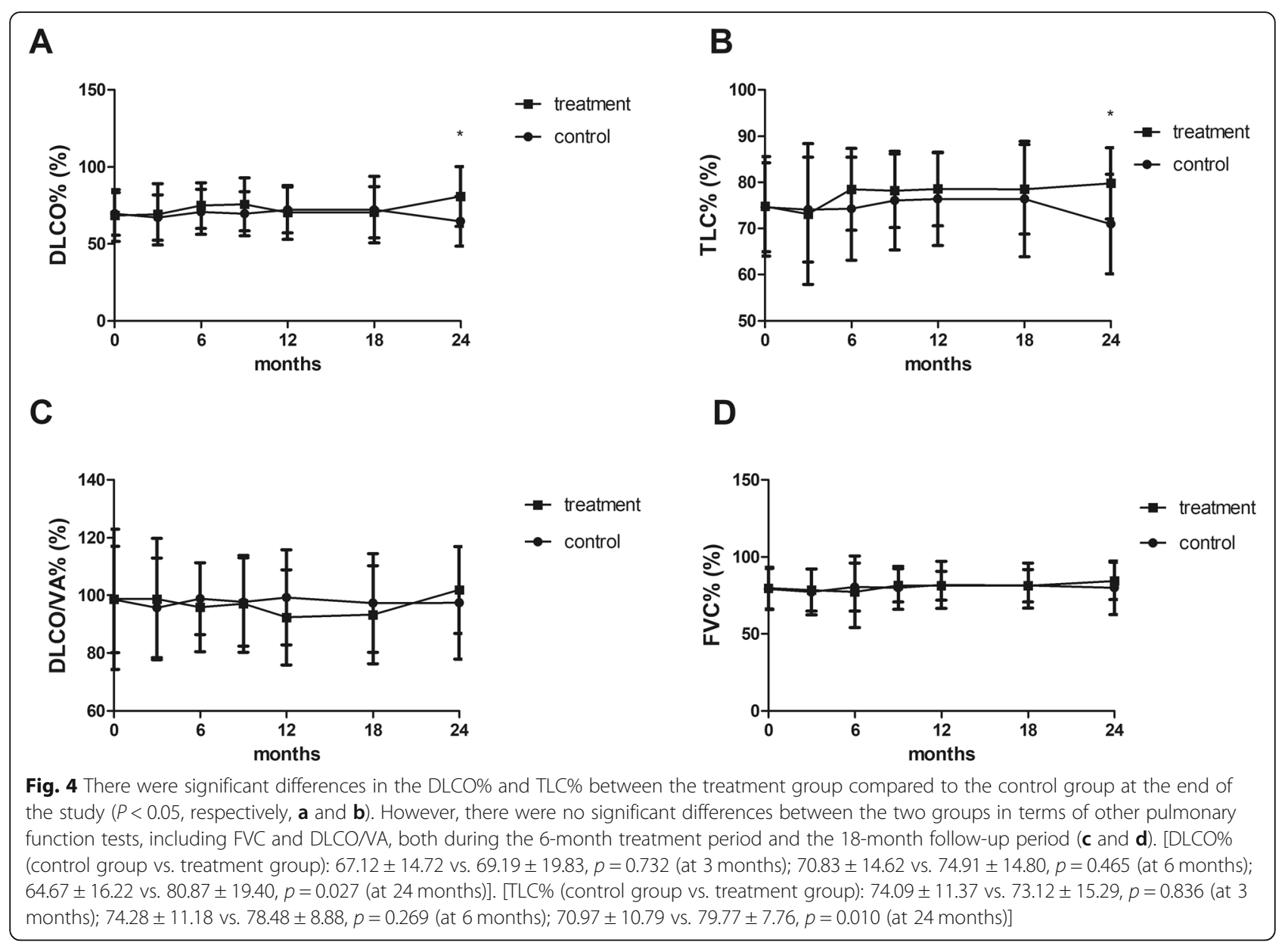

significantly improved, though they concluded that clinical benefits were not significant [25]. There are two major differences in design between our study and Tazawa et al's study as follows: (1) Tazawa et al. recruited patients with $\mathrm{PaO}_{2}$ of less than $70 \mathrm{mmHg}$ (or less than $75 \mathrm{mmHg}$ with symptoms), with the average $\mathrm{PaO}_{2}$ being $66.4 \pm 8.66 \mathrm{mmHg}$ and $68.8 \pm 8.96 \mathrm{mmHg}$ in the GM-CSF group and control group respectively. Meanwhile, we recruited patients with a DSS of between 1 and 3 inclusive, 11/19 from our GM-CSF group and 13/ 17 from our control group had a $\mathrm{PaO}_{2}$ of over 70 $\mathrm{mmHg}$, with an average $\mathrm{PaO}_{2}$ of $77.51 \pm 8.53 \mathrm{mmHg}$ in the GM-CSF group and $76.88 \pm 11.23 \mathrm{mmHg}$ in the control group respectively. (2) While both trials used 6months of treatment, Tazawa et al. used $125 \mu \mathrm{g}$ bid continuously, while we used $150 \mu \mathrm{g}$ bid for 3 months and then $150 \mu \mathrm{g}$ qd for 3 months. We found no significant response in the primary endpoint as measured by A$\mathrm{aDO}_{2}$. The reasons for the lack of response in our group may be related to the relatively good baseline oxygen content levels in our patients, making changes of this indicator less obvious. Based on our study and on previous papers, the benefits of GM-CSF treatment for aPAP patients with a $\mathrm{PaO}_{2}$ of over $70 \mathrm{mmHg}$ (DSS 1 and 2) may be very limited. There were not enough DSS3 cases $\left(\mathrm{PaO}_{2} 60-70 \mathrm{mmHg}\right)$ in our study for subgroup analysis. However, Tazawa, et al. has answered this question with a randomized placebo-controlled study. We believe GMCSF could be beneficial for those with a $\mathrm{PaO}_{2}$ of less than $70 \mathrm{mmHg}$. Additionally and critically, a significant difference in DLCO, which is a relatively reliable parameter to track improvement in aPAP patients, was observed after 24 months. This suggests that inhaled GMCSF should be provided to patients in a personallytailored manner, providing the drug for as long as is necessary for patients to respond to the drug $[22,26]$. Longer treatment periods may be necessary for future clinical trials to confirm the efficacy of the inhaled GMCSF in aPAP over the long term.

We found that inhaled GM-CSF therapy is a welltolerated choice for aPAP patients as previous studies showed $[9,11,21,22]$. Although more than half of our 


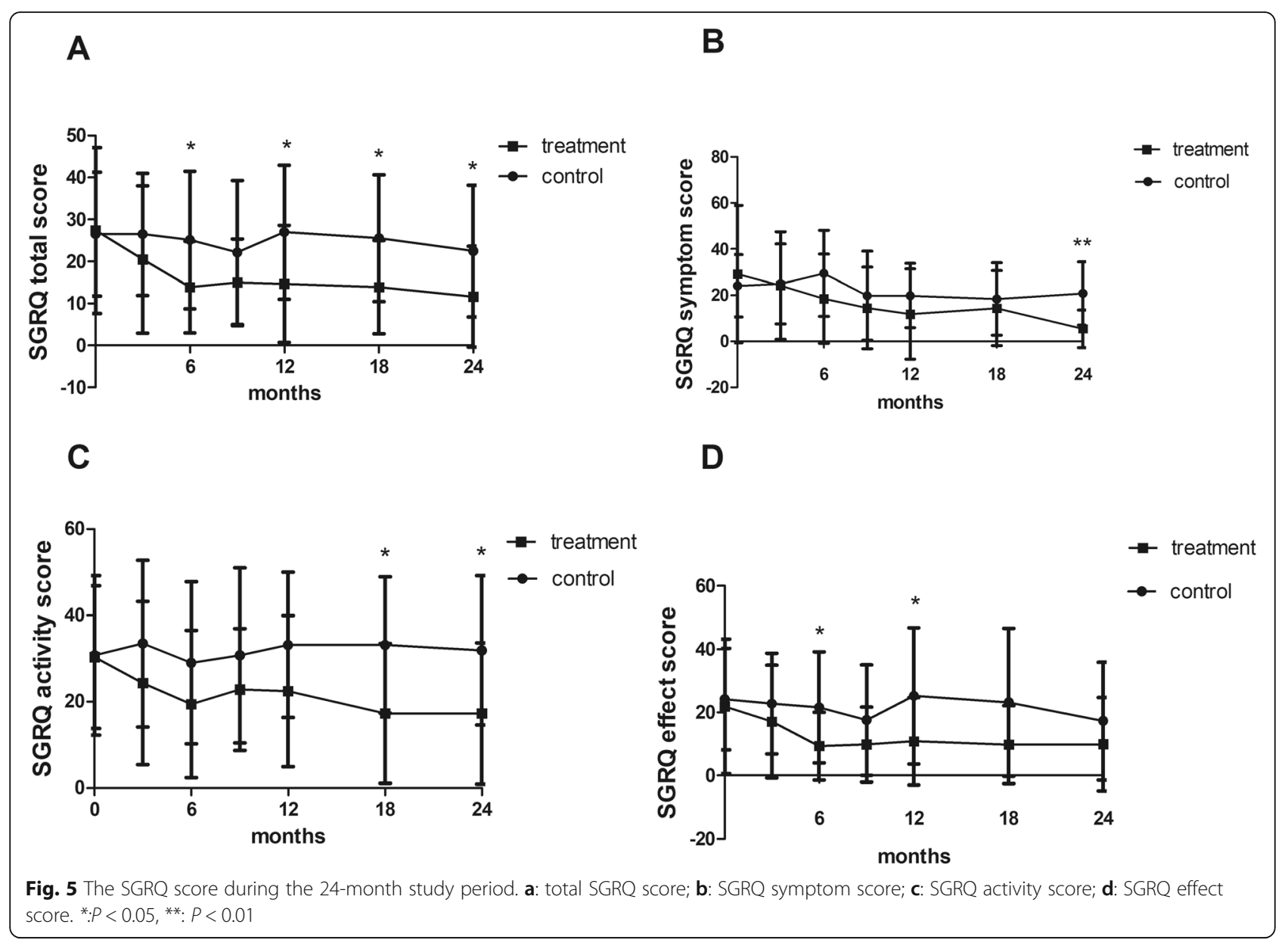

patients in the GM-CSF group were found to have slight increases in amino-transferase levels, and a number of abnormal liver function results were observed in the GM-CSF treatment group, the increases in transaminase levels were all slight and no medical intervention was needed for any of the patients. All patients remained in

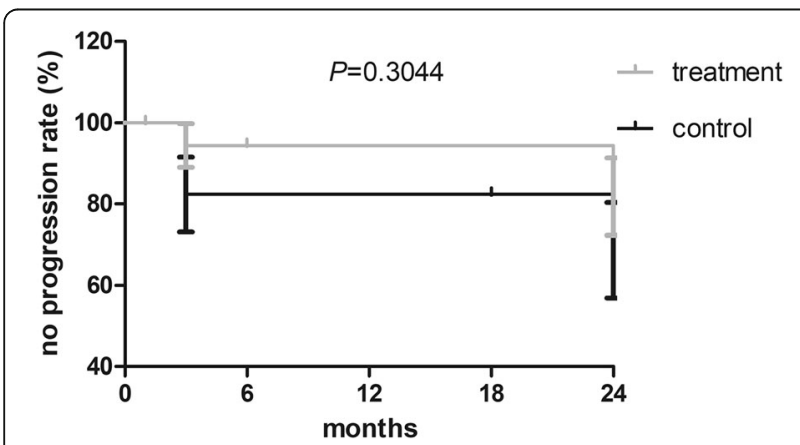

Fig. 6 There was no significant difference between the treatment and control groups in terms of no disease progression rate (measured by time to rescue therapy) over the 24 month duration of the study. $P>0.05$ stable condition or gradually improved after the cessation of alcohol and stopping intake of possibly related combination medicines. Therefore, inhaled GM-CSF therapy is a safe and convenient choice for patients.

Our research has some limitations. Firstly, the sample size of the study was small, and there were not enough DSS3 patients for analysis. Our estimated target sample size was based on prior results, done using a patient population with greater disease severity [11], which may have caused an underestimation of the sample size actually needed. Secondly, more patients from the control group, compared to patients from the GM-CSF group, dropped out of the study during the observation period, which may have affected the evaluation of effectiveness when comparing these two groups. Thirdly, the patients in our study did not receive a tailored dosage of GM-CSF treatment, nor did they receive prolonged therapy after the initial 6 months of treatment, which may have caused some latent responders, requiring higher dosages or longer treatment time for a positive response, to remain hidden. 
Table 4 The side-effect of patients with aPAP during the GM-CSF treatment and follow up period

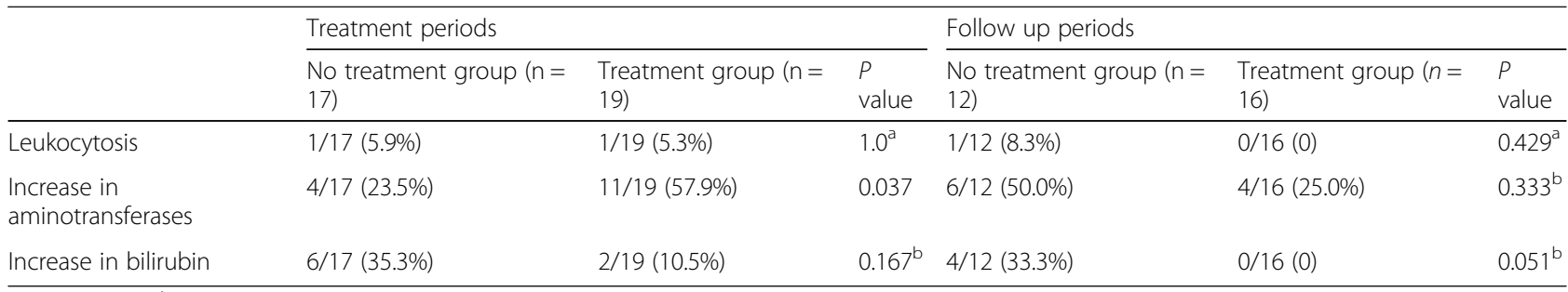

${ }^{a}$ : Fisher $X^{2}$ test; ${ }^{b}$ : continuous correction $X^{2}$ test

\section{Conclusions}

Six months of inhaled GM-CSF treatment had no effects on the alveolar-arterial oxygen gradient in patients with mild to moderate pulmonary alveolar proteinosis. At the dosage we used, there were changes in some clinical or laboratory measures, but no clinically important changes were noted at the end of study. Our study is an important complement for efficacy in aPAP patients with mild to moderate disease severity.

\section{Supplementary information}

Supplementary information accompanies this paper at https://doi.org/10. 1186/s13023-020-01450-4.

Additional file 1: Supplemental Table 1. The secondary end point of clinical parameter changes in the 18 months observational periods after 6 months inhaled GM-CSF treatment

\section{Abbreviations}

$\mathrm{A}-\mathrm{aDO} 2$ : Alveolar arterial oxygen gradient; ABG: Arterial blood gas analysis; ALT: Alanine aminotransferase; aPAP: Autoimmune pulmonary alveolar proteinosis; AST: Aspartate aminotransferase; BAL: Bronchoalveolar lavage; $\mathrm{CT}$ : Computed tomography; DLCO: Diffusing capacity for carbon monoxide; DLCONA: Diffusing capacity for carbon monoxide corrected for alveolar volume; DLCO\%: Percentage of diffusion capacity predicted; DSS: Disease severity score; $\mathrm{FEV}_{1}$ : Forced expiratory volume in the first second; FVC: Forced vital capacity; GGO: Ground-glass opacities; GM-CSF: Granulocyte macrophage colony stimulating factor; HRCT: High-resolution computed tomography; $\mathrm{PaO}_{2}$ : Arterial oxygen partial pressure; $\mathrm{PUMCH}$ : Peking Union Medical College Hospital; SGRQ: St Grorge Respiratory questionnaire; TBLB: Transbronchial lung biopsy; TLC\%: Percentage of total lung capacity predicted; WLL: Whole lung lavage; 6MWD: 6 min walking distance

\section{Acknowledgements}

The authors would like to thank Leilei Zhang for her help with the data entry.

\section{Authors' contributions}

$X T$ and KFX designed, obtained consent, and drafted the manuscript; KFX and $Y X$ reviewed the eligibility of the patients' enrollment. $X T, Y Y, L C, W X, X L$, $J W, Y Z, S M$ and $Y X$ followed up patients. XS and WS reviewed the CT scan and did quantity analysis of chest $C T$ for the patients. YY, XG, WX collected data; XT, XG, LL, YS and KFX made data analysis and interpretation. YS and LC drafted the manuscript. All authors read and approved the final manuscript.

\section{Funding}

The National Key Research and Development Program of China (2016YFC0901502), National Nature Science Foundation of China (81570061), the Chinese Academy of Medical Sciences (CAMS) Initiative for Innovative Medicine (2017-12 M-2-001, 2018-12 M01-003).

\section{Availability of data and materials}

The data of our patients is available in the department of medical records at PUMCH and the Affiliated Drum Tower Hospital of Nanjing University Medical School. This data can be released with the agreement of the patients and is available from the corresponding author upon reasonable request.

\section{Ethics approval and consent to participate}

The study was approved by the institutional review board of PUMCH (Approval No. S-717) and reviewed by the institutional review boards at the Affiliated Drum Tower Hospital of Nanjing University Medical School. All participants gave informed written consent prior to enrollment.

\section{Consent for publication}

Consent for publication was obtained from all participants.

\section{Competing interests}

This work was supported partly by the North China Pharmaceutical Corporation (NCPC) and Beijing Yikang Healthcare Technology Co. Ltd. Both companies were not involved in the data analysis and interpretation. The drug was donated by NCPC.

\section{Author details}

${ }^{1}$ Department of Pulmonary and Critical Care Medicine, Peking Union Medical College Hospital, Chinese Academy of Medical Sciences \& Peking Union Medical College, Beijing, China. ${ }^{2}$ Department of Pulmonary and Critical Care Medicine, The Affiliated Drum Tower Hospital of Nanjing University Medical School, Jiangsu, China. ${ }^{3}$ Department of Radiology, Peking Union Medical College Hospital, Chinese Academy of Medical Sciences \& Peking Union Medical College, Beijing, China. ${ }^{4}$ Emergency Center, Beijing Tongren Hospital, Capital Medical University, Beijing, China. ${ }^{5}$ Department of Biochemistry, Faculty of Medicine and Dentistry, University of Alberta, Edmonton, Canada.

Received: 18 March 2020 Accepted: 23 June 2020

Published online: 02 July 2020

\section{References}

1. Trapnell BC, Whitsett JA, Nakata K. Pulmonary alveolar proteinosis. N Engl J Med. 2003;349(26):2527-39.

2. Shende RP, Sampat BK, Prabhudesai P, Kulkarni S. Granulocyte macrophage colony stimulating factor therapy for pulmonary alveolar proteinosis. J Assoc Physicians India. 2013;61(3):209-11.

3. Inoue Y, Trapnell BC, Tazawa R, Arai T, Takada T, Hizawa N, Kasahara Y, Tatsumi K, Hojo M, Ichiwata T, et al. Characteristics of a large cohort of patients with autoimmune pulmonary alveolar proteinosis in Japan. Am J Respir Crit Care Med. 2008;177(7):752-62.

4. Khan A, Agarwal R, Aggarwal AN. Effectiveness of granulocyte-macrophage colony-stimulating factor therapy in autoimmune pulmonary alveolar proteinosis: a meta-analysis of observational studies. Chest. 2012;141(5): 1273-83.

5. Tazawa R, Inoue Y, Arai T, Takada T, Kasahara Y, Hojo M, Ohkouchi S, Tsuchihashi Y, Yokoba M, Eda R, et al. Duration of benefit in patients with autoimmune pulmonary alveolar proteinosis after inhaled granulocytemacrophage colony-stimulating factor therapy. Chest. 2014;145(4):729-37.

6. Uchida K, Nakata K, Carey B, Chalk C, Suzuki T, Sakagami T, Koch DE, Stevens C, Inoue Y, Yamada Y, et al. Standardized serum GM-CSF autoantibody 
testing for the routine clinical diagnosis of autoimmune pulmonary alveolar proteinosis. J Immunol Methods. 2014;402(1-2):57-70.

7. Uchida K, Nakata K, Trapnell BC, Terakawa T, Hamano E, Mikami A, Matsushita I, Seymour JF, Oh-Eda M, Ishige I, et al. High-affinity autoantibodies specifically eliminate granulocyte-macrophage colonystimulating factor activity in the lungs of patients with idiopathic pulmonary alveolar proteinosis. Blood. 2004;103(3):1089-98.

8. Li Y, Tian X, Gui Y, Ma A, Li X, Zeng N, Zhang P, Li G, Xu K. Serum markers in patients with idiopathic pulmonary alveolar proteinosis. Zhonghua Jie He He Hu Xi Za Zhi. 2014;37(7):497-501.

9. Tazawa R, Hamano E, Arai T, Ohta H, Ishimoto O, Uchida K, Watanabe M, Saito J, Takeshita M, Hirabayashi Y, et al. Granulocyte-macrophage colonystimulating factor and lung immunity in pulmonary alveolar proteinosis. Am J Respir Crit Care Med. 2005;171(10):1142-9.

10. Coates AL, Dinh L, MacNeish CF, Rollin T, Gagnon S, Ho SL, Lands LC. Accounting for radioactivity before and after nebulization of tobramycin to insure accuracy of quantification of lung deposition. J Aerosol Med. 2000;13(3):169-78.

11. Tazawa R, Trapnell BC, Inoue Y, Arai T, Takada T, Nasuhara Y, Hizawa N, Kasahara Y, Tatsumi K, Hojo M, et al. Inhaled granulocyte/macrophagecolony stimulating factor as therapy for pulmonary alveolar proteinosis. Am J Respir Crit Care Med. 2010;181(12):1345-54.

12. Sui X, Du Q, Xu KF, Tian X, Song L, Wang X, Xu X, Wang Z, Wang Y, Gu J, et al. Quantitative assessment of pulmonary alveolar Proteinosis (PAP) with ultra-dose CT and correlation with pulmonary function tests (PFTS). PLoS One. 2017;12(3):e0172958.

13. Awab A, Khan MS, Youness HA. Whole lung lavage-technical details, challenges and management of complications. J Thorac Dis. 2017;9(6):1697-706.

14. Seymour JF, Presneill JJ. Pulmonary alveolar proteinosis: progress in the first 44 years. Am J Respir Crit Care Med. 2002;166(2):215-35.

15. Gay P, Wallaert B, Nowak S, Yserbyt J, Anevlavis S, Hermant C, Lovis A, Menard O, Maitre B, Vandemoortele T, et al. Efficacy of whole-lung lavage in pulmonary alveolar Proteinosis: a multicenter international study of GELF. Respiration. 2017;93(3):198-206

16. Zhao YY, Huang H, Liu YZ, Song XY, Li S, Xu ZJ. Whole lung lavage treatment of Chinese patients with autoimmune pulmonary alveolar Proteinosis: a retrospective long-term follow-up study. Chin Med J. 2015;128(20):2714-9.

17. Byun MK, Kim DS, Kim YW, Chung MP, Shim JJ, Cha SI, Uh ST, Park CS, Jeong $\mathrm{SH}$, Park YB, et al. Clinical features and outcomes of idiopathic pulmonary alveolar proteinosis in Korean population. J Korean Med Sci. 2010;25(3):393-8.

18. Papiris SA, Tsirigotis $P$, Kolilekas L, Papadaki G, Papaioannou Al, Triantafillidou C, Papaporfyriou A, Karakatsani A, Kagouridis K, Griese M, et al. Pulmonary alveolar proteinosis: time to shift? Expert Rev Respir Med. 2015;9(3):337-49.

19. Kavuru MS, Sullivan EJ, Piccin R, Thomassen MJ, Stoller JK. Exogenous granulocyte-macrophage colony-stimulating factor administration for pulmonary alveolar proteinosis. Am J Respir Crit Care Med. 2000;161(4 Pt 1):1143-8.

20. Seymour JF, Presneill JJ, Schoch OD, Downie GH, Moore PE, Doyle IR, Vincent JM, Nakata K, Kitamura T, Langton D, et al. Therapeutic efficacy of granulocytemacrophage colony-stimulating factor in patients with idiopathic acquired alveolar proteinosis. Am J Respir Crit Care Med. 2001;163(2):524-31.

21. Wylam ME, Ten R, Prakash UB, Nadrous HF, Clawson ML, Anderson PM. Aerosol granulocyte-macrophage colony-stimulating factor for pulmonary alveolar proteinosis. Eur Respir J. 2006;27(3):585-93.

22. Papiris SA, Tsirigotis P, Kolilekas L, Papadaki G, Papaioannou Al, Triantafillidou C, Papaporfyriou A, Karakatsani A, Kagouridis K, Griese M, et al. Long-term inhaled granulocyte macrophage-colony-stimulating factor in autoimmune pulmonary alveolar proteinosis: effectiveness, safety, and lowest effective dose. Clin Drug Investig. 2014;34(8):553-64.

23. Ohkouchi S, Akasaka K, Ichiwata T, Hisata S, lijima H, Takada T, Tsukada H, Nakayama H, Machiya Jl, Irokawa T, et al. Sequential granulocytemacrophage Colony-stimulating factor inhalation after whole-lung lavage for pulmonary alveolar Proteinosis. A Report of Five Intractable Cases. Ann Am Thorac Soc. 2017;14(8):1298-304.

24. Ding J, Xiao Y, Dai J, Miao L, Qiu Y, Chen L, Jiang H, Cai H. Effectiveness and safety of inhaled granulocyte-macrophage colony-stimulating factor therapy in idiopathic pulmonary alveolar proteinosis. Zhonghua Yi Xue Za Zhi. 2015;95(34):2766-70.

25. Tazawa R, Ueda T, Abe M, Tatsumi K, Eda R, Kondoh S, Morimoto K, Tanaka T, Yamaguchi E, Takahashi A, et al. Inhaled GM-CSF for pulmonary alveolar Proteinosis. N Engl J Med. 2019:381(10):923-32

26. Tazawa R, Kitamura N, Nakata K. Inhaled GM-CSF for Pulmonary Alveolar Proteinosis. Reply. N Engl J Med. 2020;382(2):198.

\section{Publisher's Note}

Springer Nature remains neutral with regard to jurisdictional claims in published maps and institutional affiliations.
Ready to submit your research? Choose BMC and benefit from:

- fast, convenient online submission

- thorough peer review by experienced researchers in your field

- rapid publication on acceptance

- support for research data, including large and complex data types

- gold Open Access which fosters wider collaboration and increased citations

- maximum visibility for your research: over $100 \mathrm{M}$ website views per year

At $\mathrm{BMC}$, research is always in progress.

Learn more biomedcentral.com/submissions 